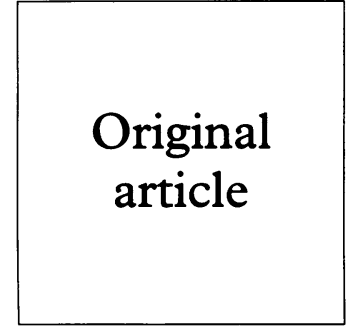

\title{
Women with HIV disease attending a London clinic
}

Lorraine Sherr, Joanna Barnes, Jonathan Elford, Adeola Olaitan, Riva Miller, Margaret Johnson

Objective: To examine ethnic, relationship, health, and mental health factors for a cohort of women with HIV infection attending an inner London clinic.

Design and methods: Structured schedules were utilised to analyse ethnic group, family, and reproduction issues, mental and physical health for 100 women drawn consecutively from attenders at an inner London HIV clinic

Results: $51 \%$ of the women were non-ethnic minority groups and $49 \%$ were from ethnic groups. HIV testing was often as a result of symptoms or partner illness. One in five had disclosed their status to one person only or no one. Ethnic minority women were more likely to restrict disclosure. Forty seven per cent of the women had 100 children with more children reported in ethnic minority families; $28 \%$ of the children had been tested for HIV and five were confirmed HIV positive; $9 \%$ of children were born after HIV diagnosis. Nineteen women reported one or more termination of pregnancy, the majority before HIV diagnosis. Three quarters had a partner of whom $56 \mathrm{knew}$ the partner's status. Women with HIV positive partners were more likely to have children. Women kept in ignorance of partner status were more likely to be ethnic minority women. Thirty two per cent had an AIDS diagnosis, diagnosed mostly in the UK. Medical and counselling service uptake was high. Gynaecological problems were common ( $49 \%$ had one or more problem) and $34 \%$ had at least one hospital admission. A wide range of counselling issues were recorded, with variations over time. Suicidal issues were relevant for $13 \%$ of women ( $69 \%$ ideation, $31 \%$ attempts). Significant life events were noted for many women with allied coping demands.

Conclusions: There are a wide range of issues for women with HIV and systematic differences between ethnic and non-ethnic women and those with or without children.

(Genitourin Med 1997;73:274-279)

Keywords: HIV; women

\section{Introduction}

HIV disease in women has unfolded amid much speculation about differences in disease course, natural history, and manifestations. This probably reflects the early reticence to grapple with the particular, ${ }^{1}$ and perhaps different, issues associated with the disease in women. ${ }^{2}$ As data emerge, ${ }^{3}$ the level of understanding is broadened. ${ }^{4}$ Early studies claimed that women had shorter disease course and more rapid decline. However, these factors may have been explained more by psychosocial factors ${ }^{5}$ than medical or biological ones. The descriptions, from uncontrolled investigations, may be explained by sex differences in access to medical care, ${ }^{6}$ unwillingness of practitioners to entertain HIV as a possible diagnosis to symptoms, and an oversight of risk in women who may not be so clearly identified or who may suffer from diagnosis delay or misdiagnosis. ${ }^{7}$ As early as 1992, Hankins and Handley $^{8}$ concluded that when age at diagnosis, AIDS presenting condition, and retroviral treatment factors were controlled for, sex effects diminished or disappeared. ${ }^{9}$ The study of HIV in women brings, of necessity, the allied demands of relationship and family. This is particularly emphasised given that HIV itself is sexually transmitted and, in turn, can cross the placenta. This latter fact has accounted for much of the research in women, because of the interest in pregnancy ${ }^{10}$ and the neonate, and has thus resulted in a comprehensive pocket of data, inevitably for women's benefit, but a blinkered shield which, while providing rich and detailed information, ${ }^{11}$ has also limited the insight for women to the months of pregnancy rather than to the population group as a whole over the course of the disease. Although much criticism has been levied at this, this "toe in the door" may have been in the ultimate interest of women. It is important that studies on women, in an attempt to redress the balance, do not overlook family, reproduction, contraception, and child rearing issues as a reaction to this early limited focus especially given the fact that many women with HIV are involved within a family or have reproduction as an issue. ${ }^{12}$

Ethnic differences were studied in women with HIV infection in Britain and Ireland. ${ }^{13}$ Important differences between black and white women in sexual history, route of transmission, disease stage at diagnosis, and pattern of AIDS defining diseases were found. ${ }^{3}$ Low $e t$ $a l^{14}$ noted that HIV infected people of subSaharan African origin living in London present with advanced disease. When the data from this group are compared with published data, survival experience is highly comparable with that recorded for HIV infected individuals born in developed countries. This study was set up to examine the interactions between sociodemographic factors of women 
with HIV, and psychosocial adjustment, challenges, and needs.

\begin{abstract}
Method
A systematic retrospective case note audit was carried out on current case notes to provide data on health, medical, and psychological needs of all women with HIV attending the hospital women's clinic, according to a standardised schedule. Case notes were drawn consecutively $(n=100)$ representing a third of the total women currently cared for $(n=$ 309 with 49 (15\%) having died since registration.) Data were gathered from both medical and counselling services. Data included basic demographic details including age, ethnic group, relationship status; diagnosis, reasons for testing for HIV, when and where diagnosed; disclosure, who woman has told of HIV status both within and outside the family; reproduction issues, pregnancies and terminations before and after HIV diagnosis, number, sex and age of any children, contraception, whether children were born before or after HIV diagnosis, and whether these children had been tested for HIV; partner, data on relationships were recorded, together with HIV status of partner if known and reasons if not tested; health details, these included frequency of clinic visits, AIDS diagnoses, drug trials involvement, gynaecological data, frequency and duration of hospital admissions; counselling details, frequency of contacts with counselling service, emotional concerns raised (initial and most recent notations), significant life events experienced since diagnosis, mention of suicide (ideation and attempt).
\end{abstract}

Table 1 Reasons given for testing for HIV

\begin{tabular}{lll}
\hline Reason given & $(n)$ & $(\%)^{\star}$ \\
\hline Investigation of symptoms & 31 & 34 \\
HIV positive partner (current or ex) & 25 & 27 \\
Blood donor & 8 & 9 \\
Antenatal screening & 7 & 8 \\
IVDU & 5 & $5 \cdot 5$ \\
Concern about promiscuous partner & 5 & $5 \cdot 5$ \\
General STD check up & 3 & 3 \\
Checking status with new partner & 2 & 2 \\
Before starting IVF treatment & 2 & 2 \\
Without consent & 2 & 2 \\
After being raped & 1 & 1 \\
Investigating baby's illness & 1 & 1 \\
\hline
\end{tabular}

ॠFigures reported as a percentage of the 92 cases where a reason for testing was recorded.

Table 2 Concerns raised with counsellor

\begin{tabular}{|c|c|c|c|c|c|}
\hline \multirow[b]{2}{*}{ Concern } & \multicolumn{2}{|c|}{ At first contact } & \multicolumn{2}{|c|}{ Most recent contact } & \multirow[b]{2}{*}{$p$ Valuef } \\
\hline & $n$ & $\%^{\star}$ & $n$ & $\% t$ & \\
\hline Own health/treatment/fears of death & 39 & 42 & 23 & 28 & $<0.01$ \\
\hline Housing/finances/employment & 25 & 27 & 31 & 38 & $<0.01$ \\
\hline Disclosure of diagnosis & 28 & 30 & 7 & 9 & ns \\
\hline Relationships & 27 & 29 & 20 & 24 & ns \\
\hline Issues around children & 28 & 30 & 16 & 20 & $<0.01$ \\
\hline Own future/isolation/lack of support & 21 & 23 & 10 & 12 & \\
\hline Fears of transmission/status of others & 13 & 14 & 3 & 4 & \\
\hline UK residency issues/court case & 15 & 16 & 11 & 13 & $<0.001$ \\
\hline Bereavements & - & - & 5 & 6 & - \\
\hline
\end{tabular}

«Figures reported as a percentage of the 93 cases which included details of concerns raised at the initial contact with the counselling services.

tFigures reported as a percentage of the 82 cases which included details of concerns raised at the most recent contact with the counselling services.

$\neq \mathrm{p}$ Values reported for associations between initial and recent concerns.

\section{Results}

The ages of the women ranged from 22 to 63 years (mean $33 \cdot 1) ; 51(51 \%)$ of the women were classified as non-ethnic minority and the remaining 49 of the women as coming from ethnic minorities including sub-Saharan Africa (44 of the 49), Asia (two), India (one), South America (one), and West Indies (one). (These figures are comparable with the total population of 309 women registered with the clinic where $38 \%$ are classified as non-ethnic minority, $52 \%$ ethnic minority, and $10 \%$ unknown.) Age did not differ significantly according to ethnicity (ethnic minorities, mean age 32.8 ; other, mean age $33 \cdot 4$ ).

\section{HIV TESTING}

Triggers for HIV testing are set out in table 1 for the 92 women for whom this was recorded.

The most common trigger was an investigation of symptoms (34\%) followed by HIV positive partner $(27 \%)$. Two women were tested without consent. Seven women were diagnosed through antenatal screening. Of these, four were from ethnic minorities, three nonethnic, three of the seven were multiparous; three of the seven chose termination of pregnancy as a result of HIV.

\section{DISCLOSURE}

Disclosure of HIV status to others is a key issue in counselling and often determines the ability to gather social or family support. Details of disclosure were recorded including relationship with those informed and number of people disclosed to. Two women had not disclosed their status to anyone, and a further 18 had told one person only. Ethnic minority women were significantly more likely to restrict disclosure to family members only $\left(50 \%\right.$ versus $23.5 \%, \chi^{2}=7 \cdot 35, \mathrm{df}=1$, $\mathrm{p}<0.01)$ and to tell no more than one person $\left(30.4 \%\right.$ versus $7 \cdot 8 \%, \chi^{2}=8 \cdot 12, \mathrm{df}=1$, $\mathrm{p}<0.01)$. There were no significant differences found according to being a mother or having a current partner.

\section{COUNSELLING ISSUES}

The main concerns raised by the women are summarised in table 2 with a comparison between first contact and most recent contact.

There were noticeable changes over time. Health, treatment, and fears of death were the major concern for $42 \%$ of the women at first contact and significantly fewer $(28 \%)$ at most recent contact. Housing, finance, and employment concerns were significantly raised as issues over time from $27 \%$ to $38 \%$. Initially, disclosure was a major issue for $30 \%$, reducing to $9 \%$ over time. Relationship concerns were present for just over a quarter of the sample, remaining fairly constant with time. Issues around children decreased from $30 \%$ to $20 \%$. A number of issues may also emerge in the future as bereavements become more prevalent with time. There were no significant associations between concerns raised and the length of time that the woman had been aware of her diagnosis. Table 3 sets out significant associations according to 
Table 3 Associations between groups and concerns raised at initial visit

\begin{tabular}{|c|c|c|c|c|c|c|c|}
\hline \multirow[b]{2}{*}{ Concern } & \multicolumn{7}{|c|}{ Groups ( $p$ Values) } \\
\hline & $\begin{array}{l}\text { Ethnic } \\
\text { minority }\end{array}$ & $\begin{array}{l}\text { Concordant } \\
\text { couple }\end{array}$ & Mothers & $\begin{array}{l}\text { Hospital } \\
\text { admission }\end{array}$ & $\begin{array}{l}\text { Mention of } \\
\text { suicide }\end{array}$ & $\begin{array}{l}\text { Drug } \\
\text { trial }\end{array}$ & $\begin{array}{l}\text { AIDS } \\
\text { diagnosis }\end{array}$ \\
\hline $\begin{array}{l}\text { Own health/treatment/fears of death } \\
\text { Housing/finances/employment }\end{array}$ & $<0.05 t$ & & & $<0.05^{\star}$ & & & $<0.05^{\star}$ \\
\hline $\begin{array}{l}\text { Disclosure of diagnosis } \\
\text { Relationships } \\
\text { Issues around children } \\
\text { Own future/isolation/lack of support } \\
\text { Fears of transmission/status of others } \\
\text { UK residency issues/court cases }\end{array}$ & $<0.05 t$ & $<0.05^{\star}$ & $<0.01^{\star}$ & & $<0.05^{\star}$ & & \\
\hline
\end{tabular}

*The concern was more likely to be raised by the group in question.

tThe concern was less likely to be raised by the group in question.

the concerns raised at both initial and most recent contact.

SUICIDE

Suicidal issues were relevant for 13 women, the majority (nine) reporting suicidal ideation and four recording attempts. One attempt occurred before the woman was diagnosed with HIV and three after diagnosis, the latter triggered by depression or bereavement. All attempts were by overdose. Of the three women who attempted suicide since HIV diagnosis:

- two had children who were born before diagnosis, the other had no children

- all were non-ethnic minority women

- one has an AIDS diagnosis

- none was diagnosed through antenatal screening

- two were from a concordant couple, one did not have a partner

- none was enrolled in a drug trial.

Women from ethnic minorities were found to be significantly less likely to have any mention of suicide than non-minority women $\left(6.1 \%\right.$ versus $19 \cdot 6 \%, \chi^{2}=4.02, \mathrm{df}=1$, $\mathrm{p}<0.05)$. There were no significant associations between the role of suicide and whether the woman had a partner, the HIV status of the couple, whether the woman had any children, who she had disclosed her HIV diagnosis to, and whether any hospital admissions were recorded in the notes.

\section{LIFE EVENTS}

Significant life events were recorded for 88 women since diagnosis. Over half (56\%) experienced relationship issues, $55 \%$ health related events, $42 \%$ movement or residency changes, $34 \%$ reported bereavements, $25 \%$ had issues around children, $18 \%$ had sudden changes, $15 \%$ had to face others in the family testing for HIV, and $13 \%$ experienced employment problems.

\section{CHILDREN}

Approximately half of the women (47) were mothers, with 100 children between them-21 having one child (nine non-ethnic and 12 ethnic), 12 having two children (five non-ethnic and seven ethnic), and 14 having three or more children (two non-ethnic and 12 ethnic). Within the total sample women from an ethnic minority were significantly more likely to have children $\left(\chi^{2}=10.20, \mathrm{df}=1, \mathrm{p}<0.01\right)$ and had larger families.
The ages of the children ranged from 2 months to 36 years (mean 10 years 7 months) The majority of the 100 children $(91 \%)$ were born before their mother was diagnosed as HIV positive. Of the nine cases where a child was born after the mother was aware of her HIV status, four of the women were pregnant when diagnosed, three had partners with HIV, one was attending a drug rehabilitation centre, and one was tested after a miscarriage. Two thirds of the babies born after HIV diagnosis were born to mothers from ethnic minorities and one third to non-ethnic minority mothers. There were no significant differences between the two groups of mothers according to whether they had children before or after being diagnosed with HIV.

\section{HIV TESTING OF CHILDREN}

Just over a quarter of the children, 28, had been tested for HIV, five of whom were confirmed as HIV positive. Three of the five HIV positive children were born before the mothers had been diagnosed themselves. Of the 23 children confirmed as HIV negative, 19 (83\%) were born before the mother's diagnosis, two $(8.5 \%)$ after, and two $(8.5 \%)$ were born to mothers who had been pregnant with them at diagnosis. The remaining three children, born after their mothers had been diagnosed as HIV positive, had not been tested.

Of the mothers, $17(36 \%)$ had had at least one of their children tested for HIV. Those mothers who had undergone a termination of pregnancy before being diagnosed as HIV positive were significantly more likely to have a child tested than those who had not $(80 \% v$ $31 \%, \chi^{2}=4.66$, df $\left.=1, p<0.05\right)$. Mothers who had children only before they were diagnosed with HIV were less likely to have their children tested than those who had given birth since diagnosis $\left(29 \% v 67 \%, \chi^{2}=4.48, \mathrm{df}=\right.$ $1, \mathrm{p}<0.05$ )

\section{TERMINATIONS}

One or more terminations of pregnancy were reported for 19 women, 12 before being diagnosed as HIV positive and seven after diagnosis. Two of the 19 women had terminations both before and after being diagnosed as HIV positive. There were no significant differences regarding termination of pregnancy with respect to ethnic grouping, whether or not the woman already had children or the HIV status of the father. Of those women undergoing a termination of pregnancy after HIV diagnosis, 


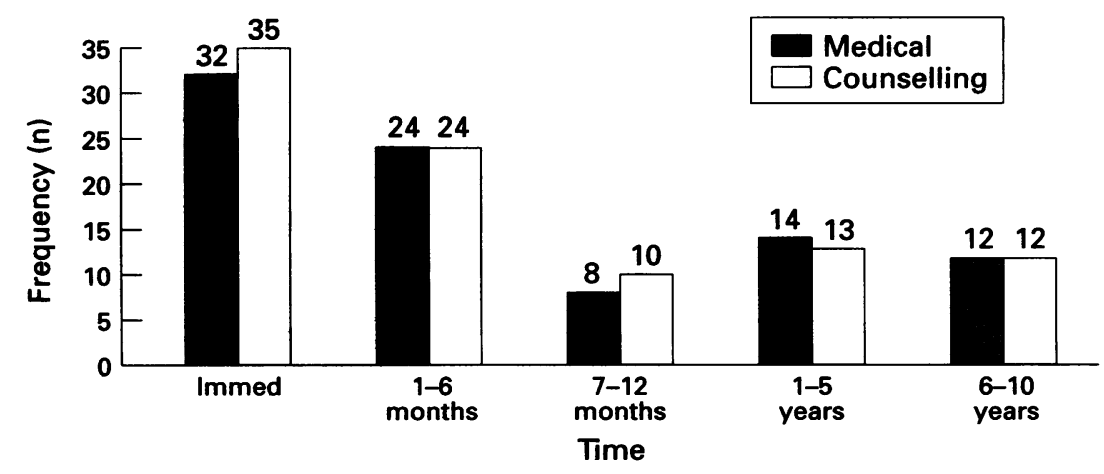

Length of time between diagnosis and first contact with medical and counselling services.

only three were tested during routine antenatal care.

PARTNERS

Three quarters (75) of the women were recorded as having a current partner. Of these, $56(75 \%)$ knew of her partner's HIV status. The majority of the couples $(35,62 \cdot 5 \%)$ were concordant (both the man and the woman being HIV positive) with the remaining 21 (37.5\%) discordant (the man being HIV negative). Fifty seven per cent of the concordant couples had children while $29 \%$ of the discordant couples had children.

Women whose current partner was HIV positive were significantly more likely to have children than those whose partner was negative $\left(30 \%\right.$ v $50 \%, \chi^{2}=4 \cdot 31$, df $=1$, $p<0.05)$, although there is no certainty that these partners were the fathers of the children. It was not clear from the notes whether relationships with partners had formed before or after the woman was diagnosed with HIV. In the $19(25 \%)$ couples where the woman did not know the HIV status of her partner she was significantly more likely to be from an ethnic minority than not $\left(\chi^{2}=9 \cdot 76\right.$, df $=1, p<0.01)$. Reasons given for a partner not testing for HIV were available in 14 of the 19 cases. These were that the partner was not aware of the woman's status and so had not been tested for HIV (six); was living abroad (five); had tested but not returned for his result (one); was due to be tested for HIV having recently learned of his wife's diagnosis (one); and did not want to test (one).

\section{MEDICAL DETAIIS}

Of the 100 women in the sample, 32 had received an AIDS diagnosis at the time of the case note review. Two (6\%) of the women with an AIDS diagnosis died during the study. These figures compare exactly with 102 (32\%) women with an AIDS diagnosis within the entire patient base of 309 . Of the 102 women with an AIDS diagnosis $47(46 \%)$ have died since registration with the clinic.

A third of the sample were diagnosed with HIV at the hospital, with $45 \%$ diagnosed at another UK hospital, and $21 \%$ diagnosed overseas. Women from ethnic minorities were significantly more likely to have been diag- nosed with HIV in the UK than the non-minority women $\left(\chi^{2}=5.85, \mathrm{df}=17\right.$ $\mathrm{p}<0.05$ ).

The length of time the women had been diagnosed as HIV positive ranged from 2 months to 12 years, with the majority of women $(57 \%)$ being diagnosed for between 1 and 5 years. Women from an ethnic minority were significantly more likely to have been diagnosed within the last 12 months, with non-ethnic minority women more likely to have longer survival $\left(\chi^{2}=10.9, \mathrm{df}=2\right.$, $p<0.01)$. Those women enrolled on a trial were significantly more likely to have been aware of their diagnosis for more than 12 months $\left(100 \% \vee 29.6 \%, \chi^{2}=14 \cdot 1\right.$, df $=2$, $\mathrm{p}<0.001)$.

CONTACT WITH WOMEN'S CLINIC

A summary of the data for length of time between diagnosis and first contact with the medical services (available for 90 women) and counselling services (available for 94 women) is shown in the figure.

These data demonstrate the close association of the provision of medical and counselling services provided by the women's clinic for the majority of women. Of the 92 cases where the information was available 84 (91\%) were recorded as having initial contact with both services at the same time.

The number of contacts with the medical services at the women's clinic ranged from 1 to 78 (mean 15.5, median 11, mode 3 ). Those women who had a larger number of contacts with the medical services were more likely to be enrolled on a drug trial (odds ratio (OR) $1 \cdot 25$, CI $(1 \cdot 13,1 \cdot 38))$. The number of contacts with the counselling services ranged from 1 to 44 (mean $7 \cdot 2$, median 5 , mode 2 ). No significant associations were found according to the number of contacts with the counselling services.

DRUG TRIALS

The case notes of 34 of the 100 women indicated that they were involved in drug trials. Women who had had children before being diagnosed with HIV were significantly less likely to be enrolled on a trial than women who did not have children before diagnosis $\left(\chi^{2}=4 \cdot 16, \mathrm{df}=1, \mathrm{p}<0 \cdot 05\right)$

\section{GYNAECOLOGICAL/GENITAL INFECTIONS}

Almost half of the women (49) had one or more gynaecological problems recorded in their notes, 33 had no problems noted, 11 had either refused a screen or were yet to be screened, and for seven there was no information in the case notes. The most common problems were vaginal thrush (18 out of 49) and herpes (14 out of 49). Abnormal smear results were reported in 24 of the 49 cases, three (13\%) of which were CIN III.

\section{HOSPITAL ADMISSIONS}

Over one third of the women (34) had at least one hospital admission recorded in their notes with hospital stay ranging from 1 to 56 days. Women with children were significantly more 
likely to have a hospital admission in their notes $\left(\chi^{2}=4.60, \mathrm{df}=1, \mathrm{p}<0.05\right)$. Perhaps as expected, there was also a significant association between having an AIDS diagnosis and being admitted to hospital $\left(\chi^{2}=12 \cdot 22\right.$, df $=$ $1, \mathrm{p}<0.01)$. No other significant associations according to groups were found.

\section{Discussion}

If services for women are to evolve to meet their needs, the nuances of their experience must be understood. In this study women are often identified at the point of investigation or while struggling with the reality of HIV infection in a loved one-partner or infant. Clearly for such women psychological preparation and emotional trauma may be greater with fewer resources to respond to it. The emerging impact of antenatal screening protocols will ramify on the population of women with HIV who are identified at this vulnerable time Although only two women had refrained from disclosing their status, a further $18 \%$ had only told one person. Disclosure restrictions were more prevalent in ethnic minority women Stigma and secrets still pervade this condition with women and may limit access to social support avenues within family networks and thus rely heavily on hospital or voluntary services.

Family issues cannot be overlooked with this group and nearly half were mothers with 100 dependent children involved. Women from ethnic minorities were more likely to have children and more likely to have larger families. On the whole the children are young (mean age of 10 years) and ongoing childcare provision during illness and after death is a current urgent need. HIV infection does not mark the end of childbearing, and a consistent group of women proceed to pregnancy and childbirth. Testing children for HIV is not automatic and may in itself be traumatic. Only 28 children had been tested, five of whom were confirmed as HIV positive. Parents chose to refuse HIV testing for three children born after HIV diagnosis. They were also less motivated to consider testing of children born before their HIV diagnosis. Termination of pregnancy is an option exercised by some women (19) in this sample, yet the majority of terminations $(68 \%)$ were before HIV diagnosis. The numbers were small, but there were no significant differences according to ethnic groups. Relationship issues were paramount in this sample. Three quarters had a current partner and $56(75 \%)$ knew the partner's status. The majority of couples in this study were concordant with $21 \quad(37 \cdot 5 \%)$ discordant. Women with positive partners were significantly more likely to have children than those with a negative partner. Women who were kept in ignorance of their partner's status were more likely to be from ethnic minorities.

Medical care and counselling support are available for these women, and work closely together in this clinic. The vast majority (91\%) have contact with both services at the same time. Thirty two per cent of the sample had received an AIDS diagnosis and two deaths were noted over the course of the study. Clinic contacts ranged in frequency from 1 to 78 in that those with larger numbers were less likely to be mothers, more likely to be in a discordant relationship, and more likely to be on a drug trial. Clearly, cause and effect cannot be inferred from retrospective data, and it may well be that drug trial participation necessitates more clinic visits. However, it is interesting that women with children had fewer visits as the literature tends to suggest that such women put the care of their children before their own. ${ }^{2}$ Counselling service use was also intense (range of 1 to 44 contacts). Ethnic minority women were significantly more likely to have been tested and diagnosed with HIV in the UK.

Drug trials were available to women, yet those with children were less likely to be enrolled on a trial. Almost half of the women had one or more genital infections, commonly thrush, herpes, and abnormal smear results in $59 \%$ of cases. Hospital admissions may be potentially traumatic with over a third experiencing at least one such admission with stays ranging from 1 to 56 days. Women with children were more likely to have hospital admissions. Not surprisingly women with AIDS diagnoses were also more likely to be admitted to hospital. Counselling needs were varied and evolved over time. Health, treatment issues, and fear of death accounted for major initial concerns and remained prevalent over the course of illness. Other issues related to housing, employment, disclosure, and relationship concerns. Bereavements may emerge with time as people in families experience illness or death. Ethnic minority women had significant associations between housing, finance employment, relationship, children, and residency issues. Those who had suicidal ideation or attempts had significant associations with housing, finance, employment relationship, and isolation/lack of social support. Clearly, this pattern of differences shows that some issues are common for all, but other issues are more prevalent or take on special proportions for subgroups. There may well be overlap between groups. None of the ethnic minority women disclosed any suicidal ideation or recorded attempts. Family issues are important for this group of women and cover not only pregnancy and termination decisions but also family challenges, concerns over children, multiple HIV testing, and partner issues.

This study shows the wide range of problems facing women and challenges the ongoing service provision to meet their needs. It points out the necessity to appreciate the great variation within the groups, representing different ethnic groups, relationship networks, family groupings, emotional needs, and healthcare needs.

This study was funded by a grant from Healthy Alliance. Acknowledgments to the EU Project on antenatal screenin policy and procedures, multinational scenario analysis, and AIDS and discrimination. Special thanks to the staff of the Royal Free Hospital for assistance in data gathering with special mention to Ms D Murray and the counselling staff. 
1 Smith JR, Murphy S, Mellers J, James M, Osborn L, Byrne $M$, et al. Risk factors of female HIV seropositive patients attending the clinic for sexually transmitted diseases at St Mary's Hospital London. Int ₹ STD AIDS 1990;1: 328-9.

2 Sherr L, Petrak J, Melvin D, Davey T, Glover L, Hedge B. Psychological trauma associated with AIDS and HIV infection in women. Counselling Psychology Quarterly infection in wom.

3 MRC Collaborative study of HIV infection in Women. Ethnic differences in women with HIV infection in Britain and Ireland. AIDS 1996;10:89-93.

4 Mann J. The Conference and the Pandemic, Plenary Address, VIII International AIDS Conference, Amsterdam, 1992

5 Niven C, Carroll D. The health psychology of women. Switzerland: Harwood Academic Publishers, 1993.

6 Moore R, Hidalgo J, Sugland B, Chaisson R. Zidovadine and the natural history of AIDS. $N$ Engl $f$ Med 1991; 324:1412-6.

$7 \mathrm{Chu} \mathrm{S}$, Buehler J, Berkelman R. Impact of the HIV epidemic on mortality in women of reproductive age. $\mathcal{F} A M A$
1990;264:225-9.

8 Hankins C, Handley M. HIV disease and AIDS in women. Current knowledge and a research agenda. $f$ Acquir Immune Defic Syndr 1992;5:957-71.

9 Hankins C. Women and HIV infection. In: Sherr L, ed. $A I D S$ in the heterosexual population, Switzerland: AIDS in the heterosexual population, Switzerland:

10 Ladner J, Leroy V, Msellati Nyiraziraje M, Van de Perre P. A chort study of factors associated with failure to return Rwanda 1992-3. AIDS 1996;10:69-75.

11 Owens DK, Nease RF Jr, Harris RA. Cost-effectiveness of HIV screening in acute care settings. Arch Intern Med 1996;156:394-404.

12 Chu S, Hanson D, Jones J. Pregnancy rates among women infected with HIV. Obstet Gynecol 1996;87:195-8.

13 Thorne C, Newell M, Dunn D, Pekcham C. Characteristics of pregnant HIV I infected women in Europe. AIDS Care 1996;8:33-42.

14 Low N, Paine K, Clark R, Mahalingham M, Pozniak A. AIDS survival and progression in black Africans living in
south London 1986-94. Genitourin Med 1996;72:12-6. 